\title{
AC 2011-1471: COMPUTER APPLICATIONS TO PROBLEM SOLVING IN SOME ENGINEERING TECHNOLOGY COURSES
}

\section{B. S. Sridhara, Middle Tennessee State University}

Dr. Sridhara is a professor in the Engineering Technology Department at Middle Tennessee State University, Murfreesboro, TN. He received his BSME degree from Bangalore University, India and MSME degrees from Indian Institute of Science, Bangalore and Stevens Institute of Technology, Hoboken, New Jersey. Dr. Sridhara received his Ph. D from Auburn University, Alabama. He has published several articles in the areas of acoustics, vibration, noise control and engineering education. Dr. Sridhara has reviewed several articles and books in his area of expertise. 


\title{
Computer Applications to Problem Solving in Some Engineering Technology Courses
}

\begin{abstract}
Use of computers and the Internet in our teaching and learning has proved to be very effective for both students and instructors. The author is currently using Desire2Learn (D2L) to teach various Engineering Technology (ET) courses including Statics, Design of Machine Elements and Vibration. Typically, he solves numerical problems related to the equilibrium of particles and rigid bodies, design of shafts, pulleys and gears, and free and forced vibration of mechanical systems. Recently the author developed some Excel programs to solve problems in the class as hand calculations are time consuming. These programs can be easily modified to solve several other problems in a particular course or area. In the class some problems are solved using hand calculations to teach the principles and methodology and additional problems are solved using the Excel programs. In Statics the students learn to calculate the position vectors and their magnitudes, the unit vectors, and the force vectors. They are also taught to formulate and solve the force equilibrium equations. In Design of Machine Elements the students learn to design shafts and belt drives for different types of loads considering the cross section, and shape, size, stress and material factors. In Vibration the students study undamped and damped vibrating systems. They learn to solve problems for the given mass, stiffness, damping factor and initial conditions using Excel and graph the oscillatory motion. In 2010 fall the author used the Excel programs in Statics and Vibration and will use them in Design of Machine Elements 2011 spring. The programs were developed in Excel because the software is available at all of Middle Tennessee State University (MTSU) computers. Also, students can afford to buy it for their home computers or laptops. Tests will be given in a computer lab so that the students can use Excel to solve problems and submit them electronically. Tests will be designed to accommodate those students who like to do hand calculations only. The author helps the students work in teams and develop their own Excel programs. He has found that for a given problem Excel takes about one-fifth of the solution time required for hand calculations. In Vibration and Design of Machine Elements the author has been assigning individual data for the take-home part of the tests and the final exam so that the students get the experience of working independently. Excel makes grading very easy particularly in such courses. The use of Excel programs for problem solving and D2L for course management helps us comply with the ABET recommendation regarding computer applications in our teaching and learning. They also address some of the ABET's a-k criteria including the ability to solve problems in their major field and team work.
\end{abstract}

\section{Introduction:}

The Engineering Technology (ET) program at MTSU has approximately 400 students in the Computer Engineering Technology (CET), Electro-Mechanical Engineering Technology (EMET) and Mechanical Engineering Technology (MET) concentrations. There are approximately 150 students in the MET concentration. The MET program that was started in the fall of 2004 has grown well and we are fortunate to be located in a highly industrialized area. All MET students are required to take several junior and senior level ET classes including ET 3830 Statics, ET 4340- Design of Machine Elements and ET 4830 - Mechanical Vibration. All our 
EMET students are required to take ET 3830 and some Aerospace majors are required to take ET 3830, 4340 and 4830. All ET majors are required to take ET 1840 - Engineering Fundamentals and in this class the author teaches students how to translate algebraic equations into the Excel format, do calculations, and generate data and graph them. Excel is available in all our lab computers and many of our students own a PC or laptop have this software available to them. The author uses the course management software (CMS), Desire2Learn (D2L) and posts all course materials for ET 1840, 3830, 4340 and 4830.

\section{ET 3830 - Statics}

Topics including scalars and vectors, the physical meaning of position vectors, unit vectors, coordinate direction angles, force vectors expressed in the Cartesian form and their mathematical representation are covered in chapter 2 of our Statics textbook. ${ }^{1}$ Equilibrium of a particle in twoand three-dimensions are discussed in chapter 3. Students learn to draw the free-body diagram of a particle acted upon by several forces and form the force equilibrium equations. Twodimensional problems can be solved for the magnitude and/or direction of unknown forces acting on a particle using the analytical method. However three-dimensional problems require the vector method as it is extremely difficult to calculate the angles made by the forces, acting on a particle, with the $x, y$ and $z$ axis. The vector method involves the calculation of the unit vector associated with each force acting on a particle, formulation of the equilibrium equations in the $x$, $y$ and $z$ directions, and solving the simultaneous equations for the unknown forces so that the particle is in static equilibrium.

In chapter 4 moment of a force is discussed and students learn the scalar and vector methods for finding the moment of a force. They also learn to find an equivalent force-couple system for a given system of forces acting on a rigid body. The equilibrium of a rigid body in two and three dimensions is discussed in chapter 5. In a three-dimensional problem a maximum of six equilibrium equations including the three force and three moment equations are to be satisfied for the body to be in static equilibrium. Chapters 2-5 form the basis for other chapters such as Structural Analysis (Trusses and Frames), Internal Forces and Moments (Beams) and Friction.

It should be emphasized here that the students need to understand the principles of statics and apply them to solve engineering problems. In the class the author interactively solves at least two problems using hand calculations for each topic in a given chapter. By the time the students learn about the static equilibrium of particles and rigid bodies they will have a good understanding of position vectors, unit vectors and force vectors. Hand calculations for finding these quantities in the in the future will be unnecessary. Therefore, the author developed some Excel programs to do the vector calculations and formulation of the equilibrium equations. $\mathrm{He}$ solved a typical numerical problem ${ }^{2}$ shown in Appendix A-1 using hand calculations and solved the same problem using the Excel program shown in Appendix A-2. The program steps were discussed in detail so that the students can relate each of them to the hand calculations. As Excel does not have the capability of solving simultaneous equations (three for the problem shown in Appendices A-1 adnA-2), they were solved using a programmable TI -83 calculator made by Texas Instruments (TI). Students were introduced to the tutorials posted on the TI website. ${ }^{3}$ Once the students felt comfortable with the Excel program, the author developed several others to solve problems on computing the moment vectors (cross product of two vectors) and the 
equilibrium of a rigid body. He does not post the Excel program on the D2L site but helps students develop their own individually or in teams. This will prevent the students from treating the program as a black box and help them better understand the principles of Statics besides promoting team work.

In the class it takes about forty five minutes to solve by hand a problem of the type shown in Appendix A-1 allowing for students interaction with the instructor. In a class test or in the final exam students get about 40 minutes to solve such a problem using hand calculations. Drawing the free-body diagram (FBD) of the particle or the rigid body properly is the first and very important step in solving static equilibrium problem. An average student takes about five minutes to draw the FBD and thirty five minutes to solve the problem using hand calculations. An Excel program will take about a minute (after the free-body diagram is drawn) to solve the same problem after the initial time and effort is put into developing the program and testing it with the problems solved in the class. Solving the simultaneous equations using a TI calculator will take about two minutes. This means the students can solve a problem of the type shown in Appendix A-1 in less than ten minutes. Statics is offered once in a year and in 2010 fall the enrollment was forty and about twenty students developed their Excel programs in consultations with the author. In the class tests fourteen students brought their own laptops to the class and solved the problems using their Excel program. This small number is mainly due the fact that Statics was taught in a classroom that had just one master workstation. We could not give the test in our CADD lab that has thirty seven workstations because another class was taught in that lab during the same time as ours. We have changed the Statics days and times for 2011 fall so that the CADD lab will be available to our students to take the test. We will also be able to compare the performance of the students who used the Excel program with those who solved problems using hand calculations only.

\section{ET 4340 - Design of Machine Elements}

This subject deals with machine elements or members that are subjected to axial, bending, torsional and fatigue loads or a combination of any of these loads. Typical members include brackets, beams, shafts, gears, bearings and belt drives. The objective will be to determine the geometry of the element considering the type of loading, material properties, and factors such as the stress factor, size factor and shape factor. The process involves a series of iterative calculations to arrive at the optimal machine element geometry subject to the recommended design factor or safety factor. ${ }^{4}$ Iterative hand calculations are very laborious and time consuming. Therefore, the author has developed Excel programs for designing machine elements that are subjected to fluctuating axial and fluctuating bending loads. A typical Excel program for the case of fluctuating bending loads is given in Appendix B. This program calculates the mean stress, amplitude of the alternating stress, actual estimated endurance strength based on the factors cited above for circular and noncircular cross-sections. The Excel program will be tried in 2011 spring and hopefully we will have some student participation results for the final version of this 2011 ASEE paper. 


\section{ET 4830 - Vibration}

In this course the students learn about the harmonic motion, free and forced vibration of damped and undamped systems. They learn to solve numerical problems for the given mass, stiffness, damping factor and initial conditions, and obtain the position of the oscillating mass as a function of time, natural frequencies and other related quantities. Problems related to the free and forced vibration of a spring-mass-damper system are much more involved ${ }^{5}$ and the computations even with a hand-held calculator are difficult and time consuming. The take-home part of a class test requires the calculation of the position of the oscillating mass for the given values of the mass, stiffness, damping factor and initial conditions. They are also required to graph the results for at least three cycles to show the decaying amplitude of oscillation. In 2010 fall the author developed an Excel program to solve such problems. He discussed the program steps in detail in the class and helped the students write their own program. He also posted the graphs on the D2L site so that the students will know what is expected. A typical student submission that shows the input data, the equations, calculated values and the graph is given in Appendix C-1. Typical individual data assigned to the students for a take-home test problem is shown in Appendix C-2.

\section{Course Objectives and Learning Outcomes Related to the Courses Discussed in This Paper}

In the fall of 2006 we prepared the objectives and learning outcomes for all MET courses as part of our preparation for the ABET accreditation. We included the following objectives in the course syllabi of the three ET courses discussed in this paper.

\section{$\underline{\text { ET } 3830 \text { Objectives }}$}

- To develop the ability of each student to analyze, set up, and apply scalar and vector methods to solve problems related to force systems; trusses; coplanar and space frames; centroids; moment of inertia; and friction.

- To develop for each student the concept of the "free-body" diagram and an appreciation for its importance in analysis.

- To encourage each student in producing engineering calculations that are neat, orderly, and professional in appearance.

\section{$\underline{\text { ET } 4340 \text { Objectives }}$}

- Understanding the concepts of stress analysis, working stress, combined stresses, failure theories, and fatigue failure.

- To be able to design machine elements subjected to direct normal, shear, torsion, bending and combined torsion and bending loads.

- To develop design techniques for shafts, fasteners, gears, bearings, and belt and chain drives considering different theories of failure.

\section{ET 4830 Objectives}

- To understand the basics of oscillatory motion of mechanical systems 
- To study mechanical vibration of one-degree, two-degree and multi-degree freedom systems

- To understand the theory of damped and undamped mechanical system in vibration

- To be able to solve mechanical vibration problems for displacement, velocity and acceleration considering free and forced vibration

- To learn about instrumentation and control related to mechanical vibration

\section{Learning Outcomes}

We developed twelve learning outcomes for our MET concentration based on the ABET a-k criteria. As has been done at several U.S. universities, we use the tests, final exam, homework and laboratory activities as direct methods to evaluate the learning outcomes. The major field test (MFT), exit interview (oral and anonymous questionnaire) and employer and/or employee survey are used as the indirect methods to evaluate the learning outcomes. ET 3830, 4340 and 4830 are three-credit courses and in each course the author gives two tests and one final exam, Each test and the final exam carry one-fourth of the final grade. There is at least one hands-on or computational team project in each class and the project(s) carry one-fourth of the final grade. Students can work independently but are encouraged to work in teams to develop their Excel programs but they are free to consult the instructor at any stage. In any case, they are required to submit professional quality results. Team work and the use the Excel programs to solve the test and/or the final exam problems address the course objectives listed above as well as the following learning outcomes.

- The ability to function effectively on teams and communicate effectively.

- The ability to utilize their knowledge of engineering materials, statics, dynamics, and strength of materials and solve problems related to mechanical systems that are stationary as well as in motion.

In the spring and fall semesters of 2011 the author plans to compare performance of those students who used the Excel programs in the test and/or the final exam with those used hand calculations only.

\section{Conclusions}

It is very important that our students understand the principles of Statics, Machine Design, Vibration and other ET courses. Solving problems using hand calculations will help them apply these principles and understand the steps involved and the author interactively solves at least two problems using hand calculations for each topic in a given chapter. However, after this the students need not go through this difficult and time-consuming method and use Excel programs instead to solve problems related to calculating position vectors, unit vectors, force vectors, dot products and cross products, working stress, design factors, natural frequencies and transmissibility. These programs can be used to solve an entire problem or treated as a computer-assisted problem solving tool. Initially students have to invest some time and effort to develop the programs and ensure their proper working. But it will only help them better understand the problem solving procedure because they will be translating the algebraic equations into the Excel format and verify the step by step computation. A quick qualitative study indicates that the Excel programs take about one-fifth of the time required for hand 
calculations. They also reduce the fatigue and human errors involved in the hand calculations especially in the iterative design process. In the classroom these programs will allow the instructor to solve more number of problems besides providing additional time for questions and answers. The Excel programs help the instructor individualize the test or project problems for each student and grade them without much difficulty. They also compliment our course objectives and address relevant student learning outcomes. The author has tried to address some concerns and questions some engineers/educators may have in the use of a computational tool such as Excel.

(a) The author feels the use of Excel (or similar software) cannot affect our students' analytical skills or their ability to do hand calculations because they learn to solve problems by hand first and then develop the Excel programs. This process can only improve their knowledge as discussed in the previous sections of this paper. Before the development of the mainframe or personal computers engineers and scientists used hand calculations in tasks such as computing eigen values/vectors, Fourier series, and Taylor series, and in solving simultaneous equations. Now we use various software to do these tasks and save a lot of time and effort. These computational tools have not reduced our analytical skills or the ability to do hand calculations. In fact, we have become more productive and efficient with the use of computers. The computational tools are like the mechanical, electrical or agricultural tools and can be very effective when used diligently. It is really up to us, the engineering educators, to use tools such as Excel without compromising the ability to do hand calculations so that our students get the best education.

(b) It is many ET graduates' dream to obtain the PE license but they are not allowed to take the FE or PE exams in the State of Tennessee. This is the situation in several other states in this region. We met with the NSPE local chapter and the State Board of Architects and Engineers asking them to permit our ET graduates to take the FE and PE exams. Our request was denied and we were told that the situation will not change. Many organizations, industries and educational institutions have changed with the changing times to better serve their clientele, customers or students. Industries have implemented the total quality management (TQM) and lean manufacturing techniques to improve their product, process or service. Educational institutions have implemented the institutional effectiveness (IE) measures and various assessment tools to continuously improve the quality of education. We hope the NCEE will change with the changing times and permit the use of PC software in the FE and PE exams. We sincerely hope The Tennessee Board of Architects and Engineers will change their current policy and make way for our ET graduates to get their PE license. In fact, the ASEE and its Engineering Technology Division can help us in both of these issues. Middle Tennessee State University (MTSU) is located in a highly industrialized area and almost all of our students get jobs in Middle Tennessee. Nissan, The Tennessee Valley Authority (TVA), Carrier Corporation, Calsonic, Vought Industries, Square-D and SW Engineering are some of our major employers. Many of these companies use Excel in their day to day work and our students fit in very well because of their knowledge of the software. We would be very glad if some of our ET graduates happen to move to a US state where they are allowed to get the PE license. The author is confident that our students will not have any problems in passing the exams because of their caliber and the experience they gain at MTSU in solving engineering problems using hand calculations. 
(c) A quantitative study of the Excel program's effectiveness while used as a computational tool requires the analysis of data collected over a period of at least two or three years. The author started using Excel in his ET classes from 2010 fall and therefore, such a study is outside the scope of this paper. There are other computational software such as MatLab, Mathematica, MathCad and The TKSolver which are as good as or better than Excel. As stated earlier we use Excel because it is available at all our lab and classroom computers. Students get it as part of the package when they buy laptops or desktops. Buying MatLab or any other software requires additional funding and the decision has to be made at the university level. Under the current budget conditions we can only use the existing hardware and software.

\section{Bibliography:}

1. Hibbeler, R. C., Engineering Mechanics - Statics, Prentice Hall, Twelfth Edition, 2010.

2. Hibbeler, R. C., Engineering Mechanics - Statics, Pp 110, Prentice Hall, Twelfth Edition, 2010.

3. TI 83 - Resource Website, http://www.itc.csmd.edu/mth/ti83/matrix/enter.htm and http://www.itc.csmd.edu/mth/ti83/matrix/rref.htm.

4. Mott, Robert L., Machine Elements in Mechanical Design, Fourth Edition, Pearson/Prentice Hall, Pp 185186, 2004.

5. William T. Thomson and Marie Dillon Dahleh, Theory of Vibration with Application, Pp 18, 30 and 51, Fifth Edition, Prentice Hall, 1998. 


\section{Appendix A1: Hand calculations for a typical problem on static equilibrium of a particle.}

\section{STATIC EQUILIBRIUM OF A PARTICLE}

Given: Point, $A(0,6,0) \mathrm{m}$; point, $C(2,0,3) \mathrm{m}$; point, $D(-1.5,0,2) \mathrm{m}$. $W=$ weight of the flower pot acting at point $A$.

Free-body diagram (FBD) of $A$

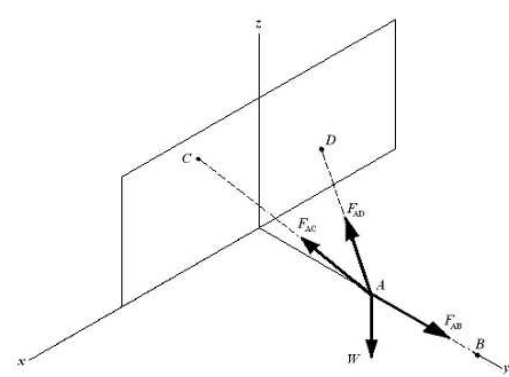

$\vec{u}_{A C}=\frac{(2-0) \vec{i}+(0-6) \vec{j}+(3-0) \vec{k}}{\sqrt{(2)^{2}+(6)^{2}+(3)^{2}}}$

$\vec{u}_{A C}=\frac{2}{7} \vec{i}-\frac{6}{7} \vec{j}+\frac{3}{7} \vec{k}$

$\vec{u}_{A D}=\frac{(-1.5-0) \vec{i}+(0-6) \vec{j}+(2-0) \vec{k}}{\sqrt{(1.5)^{2}+(6)^{2}+(2)^{2}}}=-\frac{1.5}{6.5} \vec{i}-\frac{6}{6.5} \vec{j}+\frac{2}{6.5} \vec{k}$

$\sum F_{x}=0$, gives $0+\frac{2}{7} F_{A C}-\frac{1.5}{6,5} F_{A D}=0$

$\sum F_{y}=0$, gives $F_{A B}-\frac{6}{7} F_{A C}-\frac{6}{6.5} F_{A D}=0 \cdots$ (ii)

$\sum F_{Z}=0$, gives $0+\frac{3}{7} F_{A C}+\frac{2}{6.5} F_{A D}-490.5=0$

Equation (i) gives $\frac{2}{7} F_{A C}=\frac{1.5}{6.5} F_{A D}$

$$
F_{A C}=\left(\frac{1.5}{6.5} F_{A D}\right)\left(\frac{7}{2}\right)
$$

substituting (iv) into (iii) gives

$$
\begin{aligned}
& \left(\frac{3}{7}\right)\left(\frac{1.5}{6.5} F_{A D}\right)\left(\frac{7}{2}\right)+\frac{2}{6.5} F_{A D}-490.5=0 \\
& (1.5)^{2} \frac{F_{A D}}{6.5}+\frac{2}{6.5} F_{A D}-490.5=0
\end{aligned}
$$


STATIC EQUILIBRIUM OF A PARTICLE (Continued)

$$
\begin{aligned}
(2.25+2)\left(\frac{1}{6.5}\right) F_{A D} & =490.5 \\
F_{A D} & =(490.5) \frac{(6.5)}{4.25} \\
F_{A D} & =750.2 \mathrm{~N}
\end{aligned}
$$

Substituting This into

equation (iv) gives

$$
\begin{aligned}
& F_{A C}=\left(\frac{1.5}{6.5}\right)(750.2) \frac{7}{2} \\
& F_{A C}=605.9 \mathrm{~N}
\end{aligned}
$$

substituting for $F_{A C}$ and $F_{A D}$ into equation (it) gives

$$
\begin{aligned}
& F_{A B}-\frac{6}{7}(605.9)-\frac{6}{6.5}(750.2)=0 \\
& F_{A B}=1211.85 \mathrm{~N}
\end{aligned}
$$

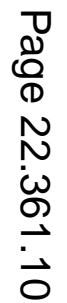


Appendix A2: Excel program for the problem in Appendix A1

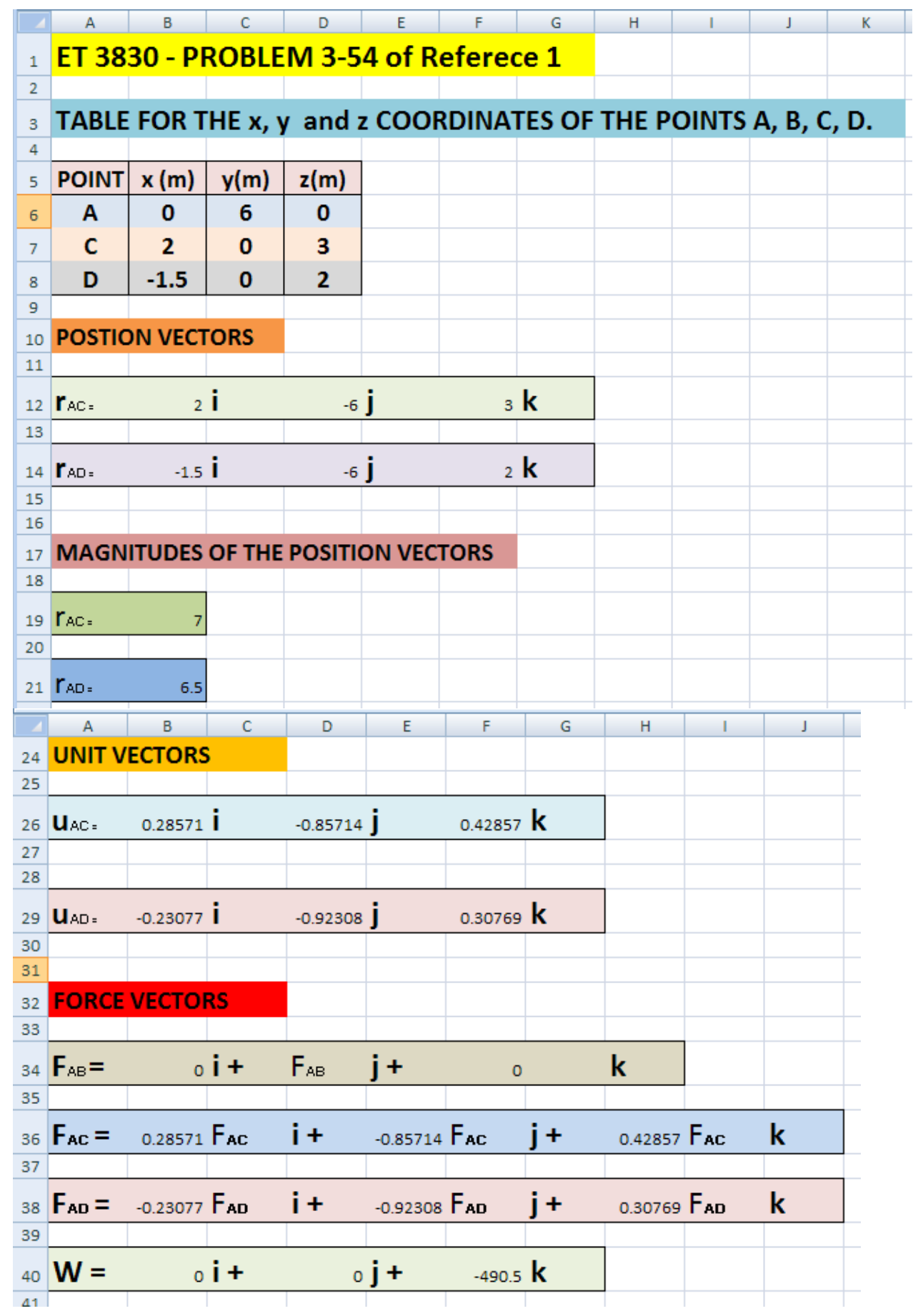




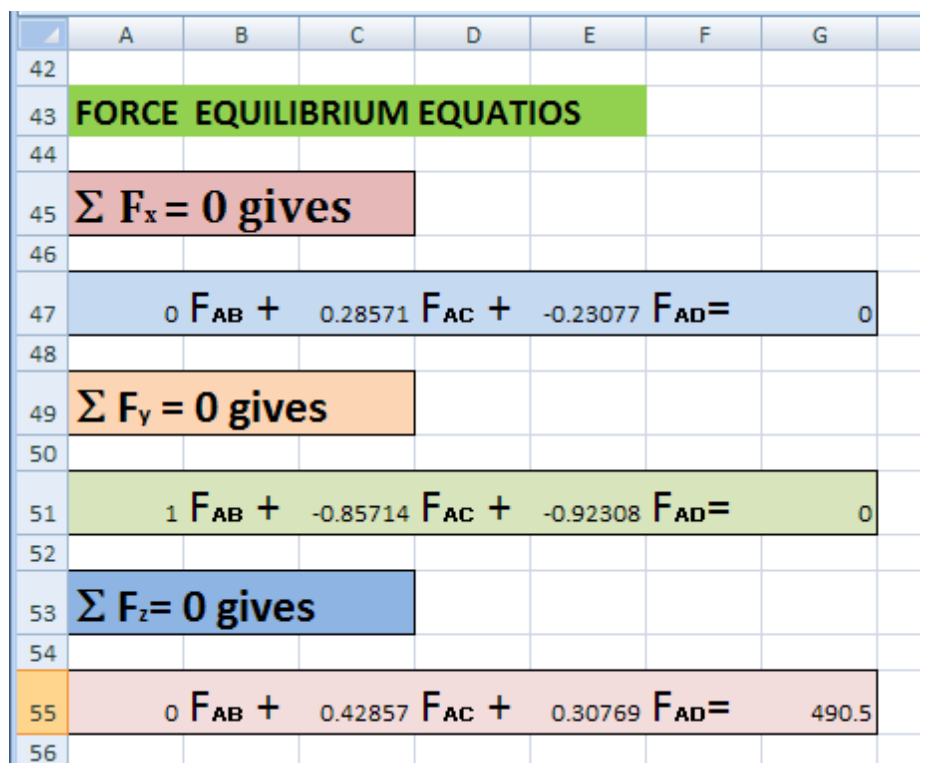

$\mathbb{D}$
$\mathbb{0}$
$\mathbb{D}$
$N$
$\stackrel{N}{\omega}$
$\stackrel{O}{. ~}$
$\dot{\vec{N}}$ 
Appendix B: Excel program for iterative design calculations of the Design Factor, $N$ (Problem 5-19 of Reference 4).

Given: A simply supported beam made of AISI 1020 hot rolled steel; length $=450 \mathrm{~mm}$; cross section $=60 \mathrm{~mm} \times 12 \mathrm{~mm}$; fluctuating load location $=1875 \mathrm{~mm}$ from the left support; the load varies from $1450 \mathrm{~N}$ to $140 \mathrm{~N}$.

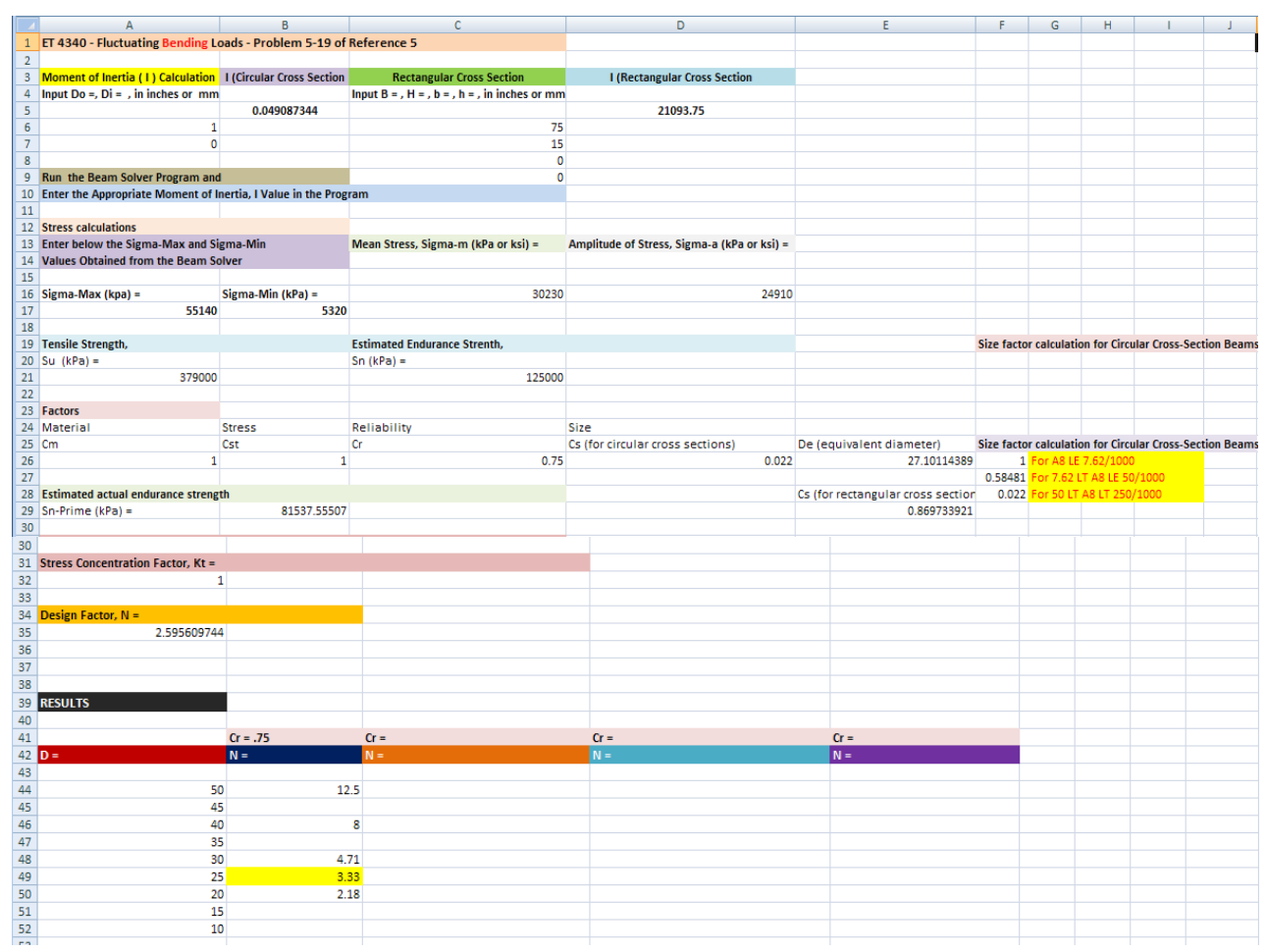




\section{Appendix C-1: Calculations and graphs for a typical spring-mass-damper system.}

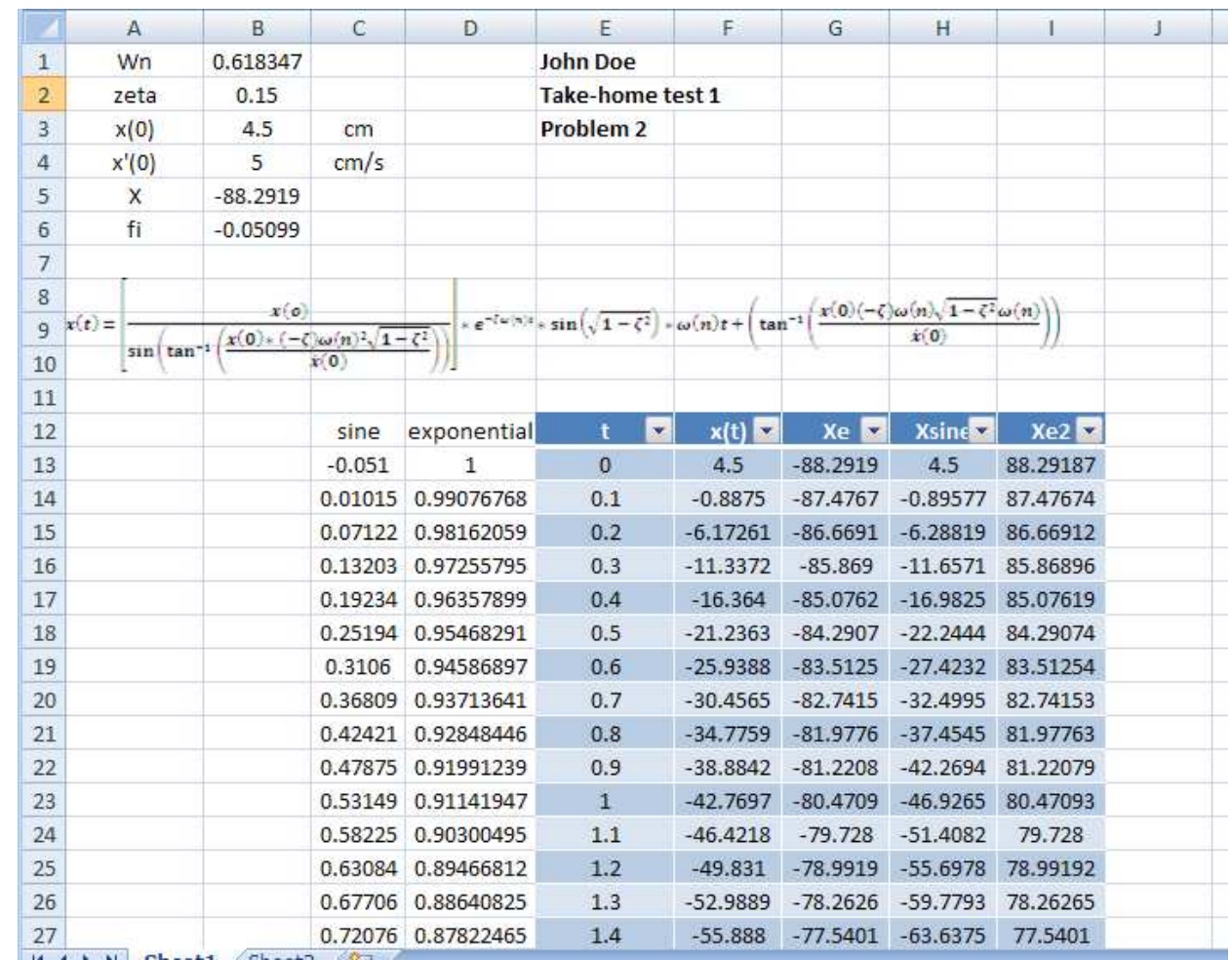

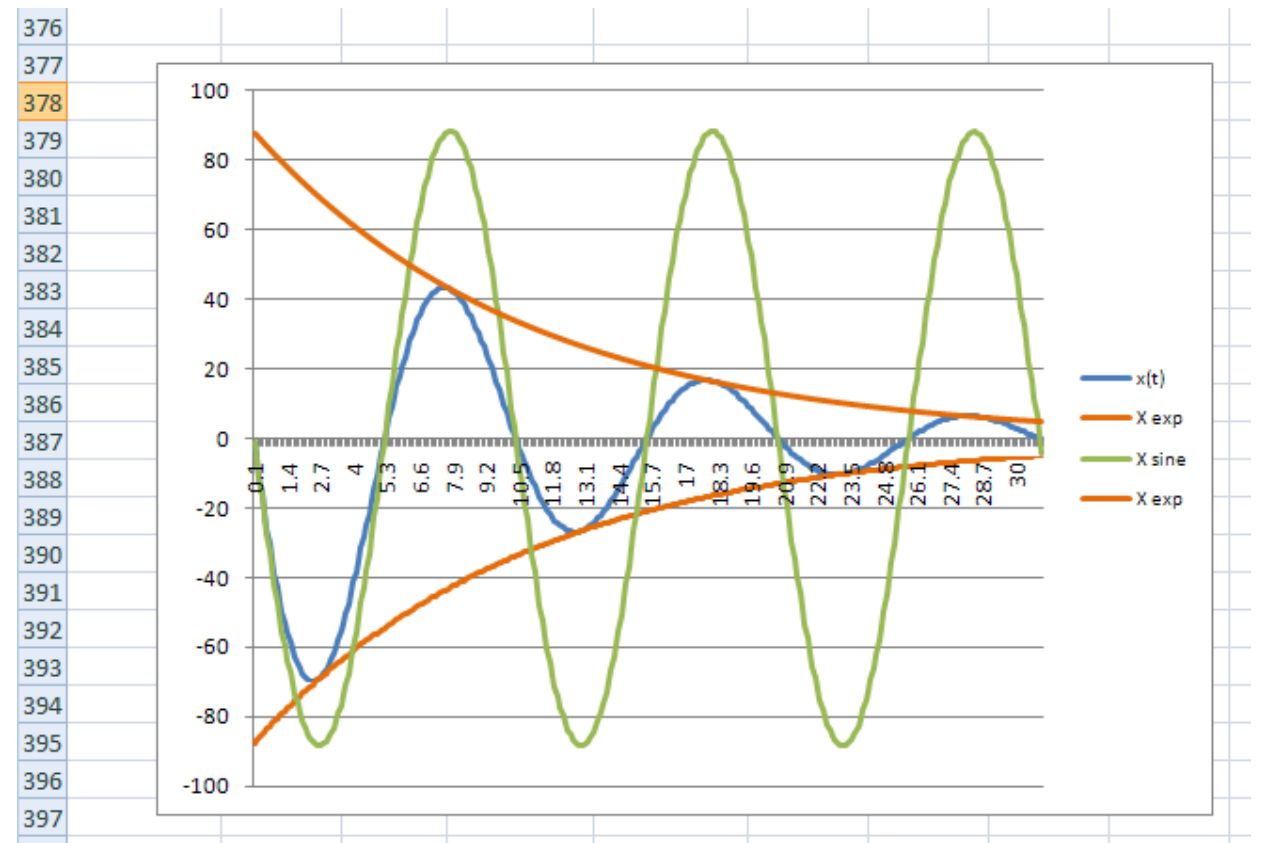


Appendix C-2: ET 4830 - Vibration, typical individual data for a take-home test.

DEPARTMENT OF ENGINEERING TECHNOLOGY

\begin{tabular}{|c|c|c|c|c|c|}
\hline \multicolumn{2}{|c|}{$\begin{array}{l}\text { ET 4830 - Vibration } \\
\text { (Instructor: } X X X X)\end{array}$} & \multicolumn{2}{|c|}{$\begin{array}{c}\text { Fall 2010 } \\
\text { (Open textbook and open notes test) }\end{array}$} & \multicolumn{2}{|c|}{ Test-1 (Take home) } \\
\hline \multicolumn{6}{|c|}{ Individual input data. } \\
\hline Last name & Mass & Stiffness & $\begin{array}{l}\text { Damping } \\
\text { Ratio }\end{array}$ & $\begin{array}{l}\text { Initial } \\
\text { Position }\end{array}$ & $\begin{array}{l}\text { Initial } \\
\text { Velocity }\end{array}$ \\
\hline$X X X X-1$ & $\mathrm{~m}=1.5 \mathrm{~kg}$ & $\mathrm{k}=0.75 \mathrm{~N} / \mathrm{cm}$ & $\zeta=0.1$ & $x(0)=4 \mathrm{~cm}$ & $\dot{x}(0)=4.5 \mathrm{~cm} / \mathrm{s}$ \\
\hline$x \times X X-2$ & $\mathrm{~m}=2.2 \mathrm{~kg}$ & $\mathrm{k}=0.85 \mathrm{~N} / \mathrm{cm}$ & $\zeta=0.22$ & $x(0)=3 \mathrm{~cm}$ & $\dot{x}(0)=4 \mathrm{~cm} / \mathrm{s}$ \\
\hline$x x x x-3$ & $\mathrm{~m}=1.7 \mathrm{~kg}$ & $\mathrm{k}=0.65 \mathrm{~N} / \mathrm{cm}$ & $\zeta=0.15$ & $x(0)=4.5 \mathrm{~cm}$ & $\dot{x}(0)=5 \mathrm{~cm} / \mathrm{s}$ \\
\hline$X X X X-4$ & $\mathrm{~m}=2.4 \mathrm{~kg}$ & $\mathrm{k}=0.95 \mathrm{~N} / \mathrm{cm}$ & $\zeta=0.3$ & $x(0)=5 \mathrm{~cm}$ & $\dot{x}(0)=3 \mathrm{~cm} / \mathrm{s}$ \\
\hline$X X X X-5$ & $\mathrm{~m}=1.25 \mathrm{~kg}$ & $\mathrm{k}=0.55 \mathrm{~N} / \mathrm{cm}$ & $\zeta=0.12$ & $x(0)=2.5 \mathrm{~cm}$ & $\dot{x}(0)=6 \mathrm{~cm} / \mathrm{s}$ \\
\hline$X X X X-6$ & $\mathrm{~m}=2.5 \mathrm{~kg}$ & $\mathrm{k}=1.05 \mathrm{~N} / \mathrm{cm}$ & $\zeta=0.32$ & $x(0)=6 \mathrm{~cm}$ & $\dot{x}(0)=5 \mathrm{~cm} / \mathrm{s}$ \\
\hline$X X X X-7$ & $\mathrm{~m}=1.6 \mathrm{~kg}$ & $\mathrm{k}=0.80 \mathrm{~N} / \mathrm{cm}$ & $\zeta=0.27$ & $x(0)=3.5 \mathrm{~cm}$ & $\dot{x}(0)=2.5 \mathrm{~cm} / \mathrm{s}$ \\
\hline \multicolumn{6}{|c|}{ 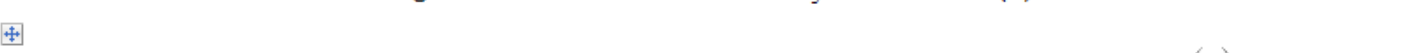 } \\
\hline$X X X X-8$ & $\mathrm{~m}=2.5 \mathrm{~kg}$ & $\mathrm{k}=0.75 \mathrm{~N} / \mathrm{cm}$ & $\zeta=0.1$ & $x(0)=6 \mathrm{~cm}$ & $\dot{x}(0)=5.5 \mathrm{~cm} / \mathrm{s}$ \\
\hline$X X X X-9$ & $\mathrm{~m}=3.2 \mathrm{~kg}$ & $\mathrm{k}=1.85 \mathrm{~N} / \mathrm{cm}$ & $\zeta=0.22$ & $x(0)=5 \mathrm{~cm}$ & $\dot{x}(0)=4 \mathrm{~cm} / \mathrm{s}$ \\
\hline$X X X X-10$ & $\mathrm{~m}=2.7 \mathrm{~kg}$ & $\mathrm{k}=0.95 \mathrm{~N} / \mathrm{cm}$ & $\zeta=0.15$ & $x(0)=6.5 \mathrm{~cm}$ & $\dot{x}(0)=5.5 \mathrm{~cm} / \mathrm{s}$ \\
\hline$X X X X-11$ & $\mathrm{~m}=1.4 \mathrm{~kg}$ & $\mathrm{k}=0.95 \mathrm{~N} / \mathrm{cm}$ & $\zeta=0.26$ & $x(0)=5 \mathrm{~cm}$ & $\dot{x}(0)=3 \mathrm{~cm} / \mathrm{s}$ \\
\hline$X X X X-12$ & $\mathrm{~m}=1.75 \mathrm{~kg}$ & $\mathrm{k}=0.85 \mathrm{~N} / \mathrm{cm}$ & $\zeta=0.12$ & $x(0)=3.5 \mathrm{~cm}$ & $\dot{x}(0)=6 \mathrm{~cm} / \mathrm{s}$ \\
\hline$X X X X-13$ & $\mathrm{~m}=2.25 \mathrm{~kg}$ & $\mathrm{k}=1.25 \mathrm{~N} / \mathrm{cm}$ & $\zeta=0.32$ & $x(0)=7 \mathrm{~cm}$ & $\dot{x}(0)=6 \mathrm{~cm} / \mathrm{s}$ \\
\hline$X X X X-14$ & $\mathrm{~m}=2.6 \mathrm{~kg}$ & $\mathrm{k}=1.80 \mathrm{~N} / \mathrm{cm}$ & $\zeta=0.37$ & $x(0)=3.5 \mathrm{~cm}$ & $\dot{x}(0)=2.5 \mathrm{~cm} / \mathrm{s}$ \\
\hline
\end{tabular}

